\title{
Five-year follow-up of a one-year self-management program for patients with COPD
}

\author{
This article was published in the following Dove Press journal: \\ International Journal of COPD \\ 8 February 2012 \\ Number of times this article has been viewed
}

\author{
Borghild K Lomundal ${ }^{1,2}$ \\ Aslak Steinsbekk ${ }^{1,2}$ \\ 'Department of Public Health \\ and General Practice, Norwegian \\ University of Science and Technology \\ (NTNU), Trondheim, Norway; \\ ${ }^{2}$ St Olavs Hospital, Trondheim, \\ Norway
}

Objective: Investigate long-term effects 4 years after the end of a 1-year self-management program (SMP) with 30 hours of education and 16 hours of physical activity in patients with chronic obstructive pulmonary disease (COPD).

Methods: Prospective observational outcome study. SMP focused on improving disease related self-care skills. Main outcome measures were health-related quality of life, HRQoL, (St Georges Respiratory Questionnaire, SGRQ total) and exercise capacity (6-minute walk test, 6MWT).

Results: Thirty patients participated, $47 \%$ women. Baseline mean age was 67 years and mean pre-bronchodilator $\mathrm{FEV}_{1}$ (forced expiratory volume in 1 second) percentage predicted was 41.3. HRQoL showed a statistical significant improvement during the 1-year intervention. Four years after the end of the program SGRQ total was similar to baseline value, 1.4 points (95\% CI: -3.6 to $6.3, P=0.580$ ). Also $6 \mathrm{MWT}$ was similar to baseline value at the same test point, $-10 \mathrm{~m}(95 \% \mathrm{CI}:-27$ to $8, P=0.262)$, and $63 \%$ reported having continued to exercise regularly a minimum of three times per week during the follow-up period.

Conclusion: The participants in a 1-year self-management program with additional training had maintained their pre-intervention level of HRQoL and exercise capacity 4 years after the end of the program. Two out of three participants had continued to exercise regularly.

Keywords: chronic obstructive pulmonary disease, outpatient, patient education, self-care ability, self-management

\section{Introduction}

Chronic obstructive pulmonary disease (COPD) is expected to be the third leading cause of death worldwide causing substantial health costs in $2020 .{ }^{1}$ Patients with COPD are anticipated to have a steady decrease in their health-related quality of life (HRQoL) and functional status. ${ }^{2}$ One intervention to increase the level of health of patients with COPD is self-management programs (SMP). ${ }^{3}$

SMPs aim to activate the participants and transfer as much as possible of the management of living with COPD from the health care provider to the patients themselves. This is helped by improving disease-related self-care skills and the patients' use of relevant knowledge and coping strategies in real-life situations and to ensure maintenance after the program. ${ }^{3}$ According to Lorig and Holman ${ }^{4}$ the SMPs should focus on medical and/or behavioral management, role management, and emotional management in order to make the patients, as much as possible, independent in their way of handling their disease. Furthermore, in patients with COPD the importance of physical exercise as a part of successful rehabilitation is well documented..$^{5-7}$
Correspondence: Borghild K Lomundal Department of Public Health and General Practice, Norwegian University of Science and Technology (NTNU), Post Box 8905 MTFS, N-749I Trondheim, Norway Tel + I 4773598768

Fax +I 4773597530

Email borghild.k.lomundal@ntnu.no 
A systematic review found a reduction in COPD-related hospital admissions, a significant reduction in dyspnea and small, but no clinically relevant improvements in HRQoL for patients with COPD participating in SMPs. ${ }^{8}$ However, the follow-up in the included studies was on the shorter side, ranging from 2 months to 1 year. As changes in patient health behavior requires time, there is a need for research on the long-term effect of SMPs. Benefits of pulmonary rehabilitation have been found to decline to pre-intervention levels during a 6-12 month period, ${ }^{9-11}$ which is probably a reason why adherence is said to be one of the most important challenges regarding rehabilitation. ${ }^{12}$ It is thus interesting to know whether SMPs help with maintaining exercise and health behavior at the end of these programs. The aim of the present study was therefore to investigate the long-term effects of a 1-year self-management program 4 years after the program ended.

\section{Materials and methods}

This was an open prospective observational outcome study conducted at an outpatient department in a hospital in Central Norway with intervention from January 2000 to February 2002. The 5-year follow-up concluded in February 2006. The trial was performed according to the principles of the Helsinki declaration. ${ }^{13}$ All the participants were informed both orally and in writing, and gave written consent to participate.

\section{Patients}

Patients were included in the study if they had been given a diagnosis of COPD from their regular physician before entering SMP and had a pre-bronchodilator forced expiratory volume in 1 second $\left(\mathrm{FEV}_{1}\right.$, forced expiratory volume in 1 second; Spirobank G; Ocean WinSpiro, Rome, Italy) lower than $75 \%$ of the predicted. The participants had to have the ability to converse, no contraindications regarding physical activity, and not have been hospitalized in the past month. A post-bronchodilator spirometric test taken at baseline was retrospectively used to classify the disease severity among the participants based on the Global Initiative for Chronic Obstructive Lung Disease (GOLD) criteria of 2007. ${ }^{14}$ To recruit participants, local general practitioners and health care personnel at the hospital were invited to refer patients to the program. All the patients invited agreed to participate in the project.

\section{Intervention}

The intervention is described in detail in a previous publication. ${ }^{15}$ The self-management program was made up of
16 gatherings, 46 hours counting 30 hours of education and 16, 1-hour exercise sessions over 1 year. Twenty-four of the 30 hours of educational sessions, and 12 of the 16 exercise sessions were carried out during the first 6 weeks. Patients were encouraged to continue to exercise thereafter. The remaining hours of education and exercise were accomplished at $12,24,36$, and 48 weeks.

The educational program was based on patient perceived concerns and problems, as well as health care professionals' experiences. The groups of five to seven patients were formed as the participants enrolled for the program, and neither age, gender, nor clinical picture were considered in the arrangement of the groups. The health care professionals participating in the delivery of the program comprised a physician, pharmacist, psychologist, nurse, social worker, physiotherapist, nutritionist, and occupational therapist. The principal aim of the program was to teach the participants basic problem-solving skills, this included problem definition and generation of possible solutions in dialog with the other participants and the health care professionals. From one lesson to the other, the participants set themselves short-term goals and reported the outcome in the group. In order to manage day-to-day decisions in response to changes in disease fluctuations, action plans were individually adjusted for all participants. The program also included how to self-treat with oral antibiotics and prednisolone. To help the participants make a better collaboration with their general practitioners, they learned how to report the trends of the disease and make informed choices about their medication. At the end of the educational sessions, all received a specially made booklet with a summary of the lectures. A physiotherapist trained in COPD care guided the 1-hour exercise sessions. Exercises were tailored to the individual, but performed in groups, and the instructor aimed to give every participant good experience of how to use their breathing during workout. Expected benefits from regular exercise were focused on in both the educational part and during the training sessions of the program, with the aim to increase exercise self-efficacy and motivate for long-term activity. A list of relevant leisure activities and exercise facilities near the participants' homes were distributed at the end of intervention. Two patients, who were current smokers at baseline, were offered an individual smoking cessation intervention consisting of 16 individual sessions lasting 6 months.

\section{Outcome measures}

Outcomes were measured before and after the self-management program and 2 and 5 years after the start of the intervention. Self-reported exercise was asked for at year 5 . 


\section{Primary outcomes}

Health-related quality of life (HRQoL) was assessed using St George's Respiratory Questionnaire (SGRQ) ${ }^{16}$ (the Norwegian version). ${ }^{17}$ The SGRQ total score was the primary outcome; the domains "symptoms", "activity", and "impact" are also reported. The scores for all scales were weighted to range from $0-100$, a score of 100 indicating worst health. A change of four units or more indicates a clinically significant change. ${ }^{18}$

A 6-minute walk test (6MWT) was used to measure "exercise capacity". ${ }^{19,20}$ Performed indoor, the walking course was $45 \mathrm{~m}$ in length and the same technician carried out all the tests. A change of $54 \mathrm{~m}$ or more in walking distance is considered clinically relevant. ${ }^{21}$

\section{Secondary outcomes}

To measure "perception of breathlessness", the Modified Borg Scale (MBS) was used during the 6MWT. ${ }^{20,22}$ MBS ranges from zero to ten, where zero is no problem. The highest value, indicating maximum disability is reported.

Coping with breathlessness generally was assessed using Breathing Problems Questionnaire (BPQ) short version ${ }^{23}$ (the Norwegian version). ${ }^{24}$ This version consists of ten items with a possible score between zero and 30 where zero indicates no problem.

"Self-efficacy" was measured using the COPD SelfEfficacy Scale (CSES). ${ }^{25}$ The Norwegian short form version (not validated) with 12 questions with a possible score between zero and 60, where zero indicates no problem, was used.

"Lung function" was measured with FVC (forced vital capacity) percentage predicted and $\mathrm{FEV}_{1}$ (forced expiratory volume in 1 second) percentage predicted.

To monitor "oxygenation" during 6MWT, we used pulse oximetry $\left(\mathrm{SpO}_{2}\right)$ (Tuffsat, Datex-Ohmeda, Louisville, $\mathrm{KY}$ ).

"Number of hospitalizations" and "days in hospital because of exacerbations" were taken from health records.

To measure whether the participants had continued to exercise during the follow-up time or not, the participants were asked face-to-face: "Have you exercised regularly, at least 30 minutes three times a week, since the end of the program?" And if "Yes": "Have you mainly taken part in organized group exercise or have you mainly exercised on your own?" The participants were also asked to describe the type of exercise performed.

\section{Analysis}

The data are presented using descriptive statistics. Missing data for those who were lost to follow-up were replaced with the last recorded value carried forward. To test for changes over time, general linear model repeated measurement analysis with Bonferroni adjustment for the confidence interval in SPSS for Windows (v 17.0; SPSS Inc, Chicago, IL) was used. An analysis of covariance (ANCOVA) was used to analyze differences between those who had exercised regularly after end of the program versus those who had not. To find covariates, a bivariate analysis between baseline values and participants exercising or not at year 5 was undertaken. The baseline values of variables that were significant $(P<0.05$ : $\mathrm{SpO}_{2}$ and $\mathrm{FEV}_{1}$ percentage predicted) were used as covariates together with the baseline value of the dependent variable. All data were analyzed using SPSS software.

\section{Results}

Of the 30 participants, two died during the intervention part of the study ( 2 and 11 months after start) and four died during the follow-up period (Figure 1). Causes of death were heart failure (two), cerebral infarct (two), and lung cancer (two). There were 24 patients remaining in the study at the end of year 5, and data were collected from all of them.

At baseline, the mean age of the patients was 67 years and $47 \%$ were women (Table 1). The mean pre-bronchodilator $\mathrm{FEV}_{1}$ percentage predicted was 41.3 , mean distance, $6 \mathrm{MWT}$, was $411 \mathrm{~m}$ and their average SGRQ total score 58.0 points (Table 2). The participants were in Stage II to IV according to the GOLD criteria. ${ }^{14}$ None of the patients were under long-term oxygen therapy nor treated with non-invasive ventilation (NIV).

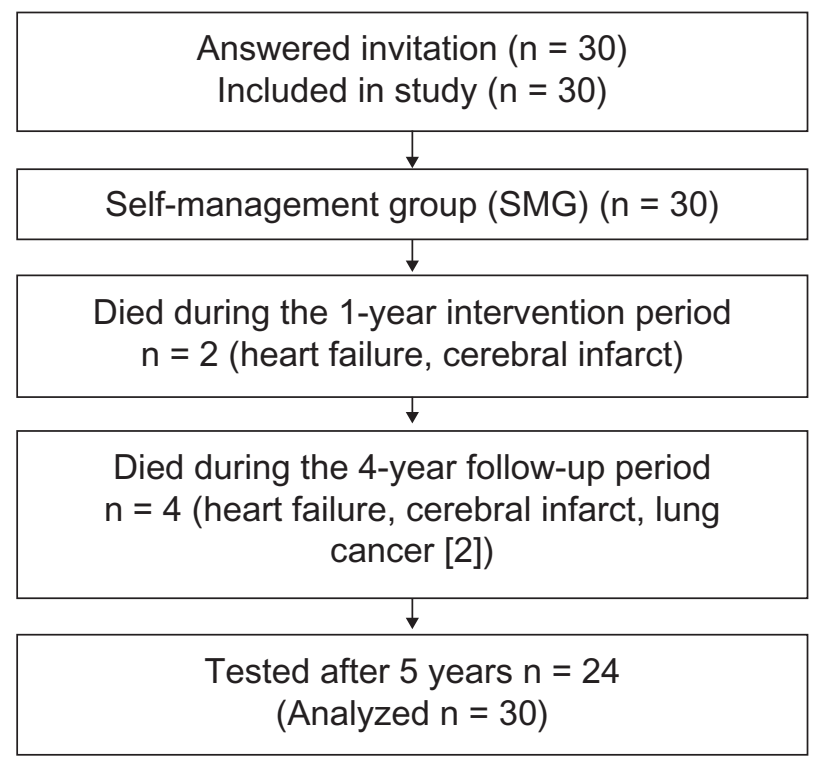

Figure I Flow chart. 
Table I Baseline demographics of the participants in the self-management program

\begin{tabular}{ll}
\hline Characteristics & Baseline \\
\hline Age (mean, min/max, SD) & $67.2(53 / 83,7.6)$ \\
Females (N, \%) & $14(46.7)$ \\
Smoking & \\
$\quad$ Current smokers (N, \%) & $2(6.7)$ \\
Ex-smokers (N, \%) & $28(93.3)$ \\
Year smoked (mean, SD) & $26(17)$ \\
Pack years (mean, SD) & $25(22)$ \\
Education (N, \%) & \\
Compulsory school & $16(53.3)$ \\
Middle level & $8(26.7)$ \\
University & $6(20.0)$ \\
\hline
\end{tabular}

Notes: Values are mean for the whole group (standard deviation, SD) or numbers of persons (\%). $N=30$. See Table 2 for other baseline values.

As shown in a previous publication, ${ }^{15}$ during the 1 -year self-management program, the participants significantly improved their HRQoL measured by SGRQ total score of -4.4 points (95\% CI: -6.3 to $-2.5, P<0.001)$, but 6MWT showed no change $-7.0 \mathrm{~m}$ (95\% CI: -16.3 to 2.3 , $P=0.137)$. Other outcome measurements showing significant improvements during the intervention were SGRQ subscale symptom $(P=0.001)$, SGRQ subscale impact $(P<0.001)$, self-efficacy measured by CSES $(P<0.001)$, and coping with breathlessness measured by BPQ total $(P=0.001)$. Changes in the other outcomes were not significant from baseline to year 1 .

\section{Long-term effects, pre-intervention to year 5}

The long-term effects were measured for 5 years on average (60 months, range 55-67 months) after the start of the program for each participant. The two patients participating in the individual smoking-cessation program over 6 months stopped smoking and were still ex-smokers at the 5-year follow-up.

Neither the primary nor the secondary outcomes showed any significant changes from pre-intervention to year 5 (Table 2). The HRQoL measured with SGRQ total showed a change of 1.4 points $(95 \% \mathrm{CI}$ : -3.6 to 6.3 , $P=0.580)$. Nine of the participants $(38 \%)$ showed a clinically significant improvement (change in SGRQ total score above four points). Exercise capacity measured with 6MWT changed $-10 \mathrm{~m}(95 \% \mathrm{CI}:-27$ to $8, P=0.262)$ (Figure 2).

Table 2 Number of participants and mean values (SE) at baseline and after I year (end of program), and at 2 and 5 years

\begin{tabular}{|c|c|c|c|c|c|}
\hline \multirow[t]{2}{*}{ Variable $^{a}$} & \multicolumn{4}{|c|}{ Test times ( $\mathrm{N}$, mean $[\mathrm{SE}])$} & \multirow{2}{*}{$\begin{array}{l}\text { Is difference between test times significant } \\
(P<0.05) ?^{\mathrm{b}}\end{array}$} \\
\hline & Baseline & I year & 2 years & 5 years & \\
\hline Participants (N) & 30 & 28 & 28 & 24 & \\
\hline SGRQ (total, points) & $58.0(1.6)$ & $53.5(1.5)$ & $54.4(1.4)$ & $59.3(1.8)$ & $\begin{array}{l}\text { Yes. From baseline to I year }(0.000) \text { and } \\
2 \text { years }(0.003) \text { and from I year to } 5 \text { years }(0.006)\end{array}$ \\
\hline 6MWT (m) & $4 I I(20.4)$ & $404(2 \mid .5)$ & $399(22.1)$ & $402(23.9)$ & No \\
\hline $\begin{array}{l}\text { Borg score (highest during } \\
6 \mathrm{MWT} \text {, points) }\end{array}$ & $6.0(0.2)$ & $5.9(0.2)$ & $5.9(0.2)$ & $6.0(0.2)$ & No \\
\hline BPQ (total points) & $12.4(0.6)$ & $10.8(0.5)$ & I2.I (0.5) & $12.8(0.7)$ & $\begin{array}{l}\text { Yes. From baseline to I year }(0.00 \mathrm{I}) \text { and from } \\
\text { I year to } 2 \text { years }(0.000) \text { and } 5 \text { years }(0.002)\end{array}$ \\
\hline CSES, points & $36.5(1.2)$ & $28.9(1.2)$ & $35.0(1.0)$ & $34.9(1.4)$ & $\begin{array}{l}\text { Yes. From baseline to I year }(0.000) \text { and from } \\
\text { I year to } 2 \text { years }(0.000) \text { and } 5 \text { years }(0.000)\end{array}$ \\
\hline $\mathrm{FEV}_{1}$ (\% predicted) & $4 I .3(2.2)$ & $41.1(2.3)$ & $40.6(2.2)$ & $40.7(2.3)$ & $\begin{array}{l}\text { Yes. From baseline to } 2 \text { years }(0.000) \text { and from } \\
\text { I year to } 2 \text { years }(0.0 \mathrm{I} \mathrm{I})\end{array}$ \\
\hline FVC (\% predicted) & $74.4(2.9)$ & $74.3(2.9)$ & $74.0(2.9)$ & $74.5(3.0)$ & No \\
\hline $\mathrm{SpO}_{2} \%$ rest & $94.1(0.4)$ & $93.9(0.4)$ & $93.9(0.4)$ & $93.9(0.4)$ & No \\
\hline Hospitalizations in last year & $0.8(0.2)$ & $0.8(0.3)$ & $0.8(0.3)$ & $0.9(0.3)$ & No \\
\hline Days in hospital in last year & $4.0(1.3)$ & $4.0(\mathrm{I} .3)$ & $3.8(1.2)$ & $4.8(1.4)$ & No \\
\hline SGRQ (symptom, points) & 5I.I (3.3) & $41.2(3.0)$ & $42.8(2.9)$ & 48.1 (3.7) & $\begin{array}{l}\text { Yes. From baseline to I year }(0.00 \mathrm{I}) \\
\text { and } 2 \text { years }(0.005)\end{array}$ \\
\hline SGRQ (activity, points) & $83.6(1.7)$ & $83.0(1.6)$ & $84.3(1.4)$ & $82.4(1.8)$ & No \\
\hline SGRQ (impact points) & $45.8(2.1)$ & 40.7 (I.9) & $40.8(1.8)$ & $49.3(2.2)$ & $\begin{array}{l}\text { Yes. From baseline to I year }(0.000) \text { and } \\
2 \text { years }(0.00 \mathrm{I}) \text {, from I year to } 5 \text { years }(0.003) \text {, } \\
\text { and from } 2 \text { to } 5 \text { years }(0.00 \mathrm{I})\end{array}$ \\
\hline
\end{tabular}

Notes: a Higher value indicates better outcome for $6 \mathrm{MWT}$, FEV $\%$ of predicted, FVC\% of predicted, and $\mathrm{SpO}_{2}$ at rest. Lower value indicates better outcome for $\mathrm{SGRQ}$ total and SGRQ subscales (range 0-100), Borg score (range 0-10), BPQ (range 0-30), CSES (range 0-60); b tested using general linear model repeated measurement analysis with Bonferroni confidence interval adjustment in SPSS for Windows ( $v$ 17.0). Values in brackets are the $P$ value for the comparisons. $N=30$ for all analyses, last recorded value carried forward for the six participants who died.

Abbreviations: 6MWT, 6-minute walk test; $\mathrm{BPQ}$, breathing problem questionnaire; CSES, COPD self-efficacy scale; $\mathrm{FEV}_{1}$, forced expiratory volume in I second; $\mathrm{FVC}$, forced vital capacity; $\mathrm{SE}$, standard error; $\mathrm{SpO}_{2}$, pulse oximetry; SGRQ, St George's Respiratory Questionnaire. 


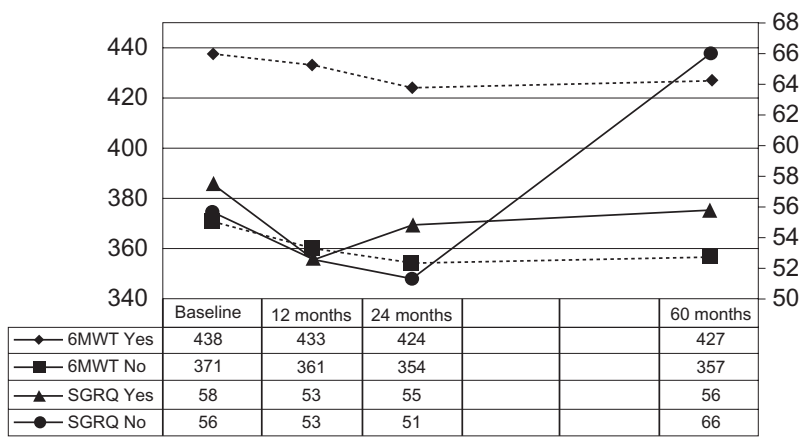

Figure 2 Changes in St George's Respiratory Questionnaire (SGRQ) total score and meters walked during 6-minute walk test (6MWT) for those who continued to exercise after end of program ("Yes") and those who did not ("No").

Note: Numbers are mean values.

Three of the participants (13\%) had a clinically relevant improvement (change in 6MWT above $54 \mathrm{~m}$ ).

Fifteen $(63 \%)$ of the participants, who were alive at year 5 , reported that they had exercised regularly, at least 30 minutes three times a week, for the last 4 years. Of these, 12 had taken part in group activities such as dancing and/or endurance training with other patients with COPD. The other three had carried out supervised exercise performance training programs at a training center. Regular walking every day was reported to have become a habit among all who had continued to exercise. Those who had stopped exercising after the end of the program, cited lack of social support, repeating exacerbations, perceived frailty, and poor health as reasons.
Table 3 shows the difference between those who had continued to exercise or not, controlling for baseline values of $\mathrm{SpO}_{2}, \mathrm{FEV}_{1}$ percentage predicted, and the outcome measure. Those who reported to have exercised on a regular basis had a statistically and clinically significantly better HRQoL (SGRQ total, estimated mean difference -12.7 points, $95 \%$ CI: -23.3 to -2.1 ), but there were no changes for exercise capacity (6MWT, estimated mean difference $-19 \mathrm{~m}, 95 \% \mathrm{CI}$ : -78 to 40 ). Those who exercised also did significantly better on SGRQ symptoms, SGRQ activity, BPQ total, number of hospitalizations, and number of days in hospital.

\section{Discussion}

Patients with COPD, who took part in a 1-year selfmanagement program, had maintained their pre-intervention level of health-related quality of life and exercise capacity 4 years after the completion of the program.

The strength of this study is the length of the followup. A limitation is that the study is neither randomized nor controlled, and in this way we are unable to control to what degree our results are attributed to the program. Furthermore, we did not collect data on the activity performed at home regarding intensity and duration before start of the study. The data on sustained physical activity after the study was based on one general question. Because of this, we do not know whether the participants in our study were more or less active compared to the time before the intervention, or

Table 3 Outcome at baseline and year 5 for those who had continued to exercise and those who had not exercised regularly after end of the program

\begin{tabular}{|c|c|c|c|c|c|c|}
\hline \multirow[t]{2}{*}{ Variables $^{a}$} & \multicolumn{2}{|c|}{$\begin{array}{l}\text { Continued to exercise after } \\
\text { end of program }(N=15)\end{array}$} & \multicolumn{2}{|c|}{$\begin{array}{l}\text { Did not continue to exercise } \\
\text { after end of program }(\mathrm{N}=9) \\
\end{array}$} & \multicolumn{2}{|c|}{$\begin{array}{l}\text { Estimated difference between } \\
\text { groups at year } 5^{\text {b }}\end{array}$} \\
\hline & Baseline & 5 years & Baseline & 5 years & Mean $(95 \% \mathrm{Cl})$ & $P$ value \\
\hline SGRQ (total, points) & $57.5(8.3)$ & $55.9(7.3)$ & $55.7(10.6)$ & $66.0(12.2)$ & $-12.7(-23.3 \text { to }-2.1)^{*}$ & 0.021 \\
\hline 6MWT (m) & $438(102)$ & $427(I 17)$ & 371 (89) & $357(133)$ & $-19(-78$ to 40$)$ & 0.510 \\
\hline Borg score (highest during & $6.0(1.4)$ & $5.5(1.3)$ & $5.8(1.2)$ & $6.4(1.2)$ & $-1.2(-2.5$ to 0.1$)$ & 0.075 \\
\hline \multicolumn{7}{|l|}{ 6MWT, points) } \\
\hline BPQ (total, points) & $12.5(2.9)$ & II.7 (2.4) & II.7 (3.6) & | $4.8(4.9)$ & $-3.8(-7.5 \text { to } 0.0)^{*}$ & 0.050 \\
\hline CSES, points & $34.5(6.2)$ & $32.5(6.1)$ & $36.8(4.9)$ & $37.7(9.2)$ & $-5.0(-12.9$ to 2.8$)$ & 0.195 \\
\hline $\mathrm{FEV}_{1} \%$ predicted & $45.9(12.3)$ & $45.7(12.4)$ & $35.3(9.6)$ & $34.1(9.4)$ & $41.8(41.1$ to 42.5$)$ & $0.08 I$ \\
\hline FVC\% predicted & $74.4(15.1)$ & $74.8(15.2)$ & $73.7(17.6)$ & $73.3(18.7)$ & 74.3 (73.4 to 75.1$)$ & 0.967 \\
\hline $\mathrm{SpO}_{2} \%$ rest & $95.5(1.6)$ & $94.9(2.0)$ & $93.2(2.3)$ & $93.4(1.7)$ & $-0.4(-1.4$ to 0.5$)$ & 0.344 \\
\hline Hospitalizations last year $(\mathrm{N})$ & $0.8(1.3)$ & $0.3(1.0)$ & $0.4(0.7)$ & $1.3(1.5)$ & $-1.5(-2.8 \text { to }-0.1)^{*}$ & 0.034 \\
\hline Days in hospital last year $(\mathrm{N})$ & $4.2(7.8)$ & $1.9(5.2)$ & $2.9(5.6)$ & $8.2(8.8)$ & $-9.6(-16.4 \text { to }-2.7)^{*}$ & 0.009 \\
\hline SGRQ symptom, points & $47.4(16.3)$ & $41.6(16.2)$ & $54.0(20.7)$ & $62.5(21.2)$ & $-24.7(-45.6 \text { to }-3.7)^{*}$ & 0.023 \\
\hline SGRQ activity, points & $83.1(9.0)$ & $78.1(8.4)$ & $82.9(11.0)$ & $85.8(8.8)$ & $-9.3(-17.9 \text { to }-0.6)^{*}$ & 0.037 \\
\hline SGRQ impact, points & $46.1(10.6)$ & $47.5(10.8)$ & $40.8(13.4)$ & $55.6(14.7)$ & $-11.0(-25.1$ to 3.0$)$ & 0.118 \\
\hline
\end{tabular}

Notes: aHigher value indicates better outcome for $6 \mathrm{MWT}, \mathrm{FEV} \%$ predicted, FVC\% predicted and $\mathrm{SpO}_{2}$ at rest. Lower values indicate better outcome for SGRQ total and SGRQ subscales (range 0-100), Borg score (range 0-10), BPQ (range 0-30), CSES (range 0-60); ${ }^{\mathrm{A}} \mathrm{ANCOVA}$ with the baseline values of SPO ${ }_{2}$, FEV, \% predicted, and the dependent variable as the covariates. " $P$ value $<0.05$; values are means for the two groups.

Abbreviations: 6MWT, 6-minute walk test; BPQ, breathing problem questionnaire; CSES, COPD self-efficacy scale; FEV , forced expiratory volume in I second; FVC, forced vital capacity; SD, standard deviation; $\mathrm{SpO}_{2}$, pulse oximetry; SGRQ, St Georges Respiratory Questionnaire. 
whether they differed from the average patient with COPD. But what we can describe is that patients with COPD doing regular training perform better, and have a better HRQoL and self-perceived dyspnea.

Although the HRQoL was on the pre-intervention level 5 years after the start of the program, it had a decline from year 2 to year 5 , a finding in line with the expected deterioration of health status. ${ }^{26}$ However, seen in a 5-year perspective, they had maintained their level of HRQoL, thus having postponed the expected extent of decline. Furthermore, in this study the participants had a very steady exercise capacity throughout the 5 years. This is contrary to the expected decline in functional performance. ${ }^{27}$ Inactivity has been found to be an important cause of disease progression in COPD, ${ }^{28}$ and Redelmeier et al showed an expected reduction in exercise capacity to a clinically relevant extent every 2 years for patients with COPD not participating in rehabilitation programs. ${ }^{21}$

All the participants in our study completed the intervention $^{15}$ and two out of three had continued regular exercising after the end of the study. These observations were encouraging and contrary to findings in studies that have shown that many participants drop out during the program or discontinue the activity after the end of the intervention. ${ }^{29-31}$ Foglio et $\mathrm{al}^{32}$ showed that patients with COPD undergoing repeated pulmonary rehabilitation programs over a period of 7 years did not show any significant worsening in exercise tolerance and HRQoL. And Heppner et $\mathrm{al}^{6}$ found that physical activity, like walking, after completing pulmonary rehabilitation, was associated with slower declines in overall HRQoL and dyspnea, during activities of daily living. In this study, those with more severe COPD were less likely to exercise 4 years after the end of the program. Patients with more severe disease might need a more aggressive intervention to keep on exercising after the end of the program.

The sustained physical activity among such a large proportion of the participants in our study is likely to be the main factor causing the positive long-term results. The question is therefore whether any of the things done in the program helped to achieve this. Based on reflections in hindsight, we think that in addition to the general content and length of the program, some factors in particular could contribute. Voluntary organizations and physiotherapists in private practice gave a short face-to-face presentation of their existing activities during the self-management program. This may have made it easier to contact and join other groups after the completion of the intervention. Positive attitudes regarding information of how to exercise and exercise self-efficacy were focused in our intervention, both predictors that have been found to be of importance regarding successful maintenance and long-term activity. ${ }^{29}$ Our intervention also included individual action plans. Early detection of exacerbations followed by appropriate actions have showed lower hospitalization rates and have also been found to be important regarding regular physical activity compared to patients who do not seek treatment. ${ }^{33}$

As many of the patients with COPD are limited in terms of ventilation during work, learning how to cope with exertional dyspnea during the exercise sessions may have made it easier to raise the general level of physical activity. ${ }^{34}$ The ability to discuss whatever they found important, both with the health care professionals and the other participants during the program, could have given the participants a sense of group support and increased self-efficacy; both are predictors found to be related to motivation for self-care and further social participation. ${ }^{35}$ However, more information is needed about why participants continue to exercise long-term after self-management programs, especially how such programs influence style of life, and new personal and social habits.

\section{Conclusion}

In this study, patients with COPD participating in a 1-year self-management program with some training maintained their pre-intervention level of health and exercise tolerance 4 years after the end of the program.

\section{Acknowledgments}

The authors acknowledge support from the Norwegian Foundation for Health and Rehabilitation and the Central Norway Health Authorities.

\section{Disclosure}

The authors report no conflict of interest in this work.

\section{References}

1. Firlei N, Lamprecht B, Schirnhofer L, Kaiser B, Studnicker M. The prevalence of COPD in Austria - the expected change over the next decade. Wien Klin Wochenschr. 2007;119(17-18):513-518. German.

2. Burge PS, Calverley PM, Jones PW, Spencer S, Anderson JA, Maslen TK. Randomised, double blind, placebo controlled study of fluticasone propionate in patients with moderate to severe chronic obstructive pulmonary disease: the ISOLDE trial. BMJ. 2000;320(7245): 1297-1303.

3. Bourbeau J, van der Palen J. Promoting effective self-management programmes to improve COPD. Eur Respir J. 2009;33(3):461-463.

4. Lorig KR, Holman H. Self-management education: history, definition, outcomes, and mechanisms. Ann Behav Med. 2003;26(1):1-7.

5. Nici L, Donner C, Wouters E, et al. American Thoracic Society/European Respiratory Society statement on pulmonary rehabilitation. Am J Respir Crit Care Med. 2006;173(12):1390-1413. 
6. Heppner PS, Morgan C, Kaplan RM, Ries AL. Regular walking and long-term maintenance of outcomes after pulmonary rehabilitation. J Cardiopulm Rehabil. 2006;26(1):44-53.

7. Lacasse Y, Goldstein R, Lasserson TJ, Martin S. Pulmonary rehabilitation for chronic obstructive pulmonary disease. Cochrane Database Syst Rev. 2006;(4):CD003793.

8. Effing T, Monninkhof EM, van der Valk PD, et al. Self-management education for patients with chronic obstructive pulmonary disease. Cochrane Database Syst Rev. 2007;(4):CD002990.

9. Ries AL, Kaplan RM, Limberg TM, Prewitt LM. Effects of pulmonary rehabilitation on physiologic and psychosocial outcomes in patients with chronic obstructive pulmonary disease. Ann Intern Med. 1995;122(11):823-832.

10. Bestall JC, Paul EA, Garrod R, Garnham R, Jones RW, Wedzicha AJ. Longitudinal trends in exercise capacity and health status after pulmonary rehabilitation in patients with COPD. Respir Med. 2003;97(2):173-180.

11. Finnerty JP, Keeping I, Bullough I, Jones J. The effectiveness of outpatient pulmonary rehabilitation in chronic lung disease: a randomized controlled trial. Chest. 2001;119(6):1705-1710.

12. Bourbeau J. Making pulmonary rehabilitation a success in COPD. Swiss Med Wkly. 2010;140:w13067.

13. World Medical Association Declaration of Helsinki: ethical principles for medical research involving human subjects. J Int Bioethique. 2004;15(1):124-129.

14. Rabe KF, Hurd S, Anzueto A, et al. Global strategy for the diagnosis, management, and prevention of chronic obstructive pulmonary disease: GOLD executive summary. Am J Respir Crit Care Med. 2007;176(6):532-555.

15. Lomundal BK, Steinsbekk A. Observational studies of a one year self-management program and a two year pulmonary rehabilitation program in patients with COPD. Int J Chron Obstruct Pulmon Dis. 2007;2(4):617-624.

16. Jones PW, Quirk FH, Baveystock CM, Littlejohns P. A self-complete measure of health status for chronic airflow limitation. The St George's Respiratory Questionnaire. Am Rev Respir Dis. 1992;145(6): 1321-1327.

17. Gallefoss F, Bakke PS, Rsgaard RS. Quality of life assessment after patient education in a randomized controlled study on asthma and chronic obstructive pulmonary disease. Am J Respir Crit Care Med. 1999;159(3):812-817.

18. Jones PW. Interpreting thresholds for a clinically significant change in health status in asthma and COPD. Eur Respir J. 2002;19(3) 398-404

19. Butland RJ, Pang J, Gross ER, Woodcock AA, Geddes DM. Two-, six-, and 12-minute walking tests in respiratory disease. Br Med J (Clin Res Ed). 1982;284(6329):1607-1608.

20. ATS statement: guidelines for the six-minute walk test. Am J Respir Crit Care Med. 2002;166(1):111-117.
21. Redelmeier DA, Bayoumi AM, Goldstein RS, Guyatt GH. Interpreting small differences in functional status: the Six Minute Walk test in chronic lung disease patients. Am J Respir Crit Care Med. 1997;155(4):1278-1282.

22. Burdon JG, Juniper EF, Killian KJ, Hargreave FE, Campbell EJ. The perception of breathlessness in asthma. Am Rev Respir Dis. 1982;126(5):825-828.

23. Hyland ME, Singh SJ, Sodergren SC, Morgan MP. Development of a shortened version of the Breathing Problems Questionnaire suitable for use in a pulmonary rehabilitation clinic: a purpose-specific, diseasespecific questionnaire. Qual Life Res. 1998;7(3):227-233.

24. Haave E, Hyland ME, Engvik H. Physical and emotional aspects of selfreported health status: a two-factor model of the short-form Breathing Problems Questionnaire. Chron Respir Dis. 2005;2(1):21-26.

25. Wigal JK, Creer TL, Kotses H. The COPD Self-Efficacy Scale. Chest. 1991;99(5):1193-1196.

26. Spencer S, Calverley PM, Sherwood Burge P, Jones PW; ISOLDE Study Group. Inhaled Steroids in Obstructive Lung Disease. Health status deterioration in patients with chronic obstructive pulmonary disease. Am J Respir Crit Care Med. 2001;163(1):122-128.

27. Kapella MC, Larson JL, Covey MK, Alex CG. Functional performance in chronic obstructive pulmonary disease declines with time. $\mathrm{Med} \mathrm{Sci}$ Sports Exerc. 2011;43(2):218-224.

28. British Thoracic Society Standards of Care Subcommittee on Pulmonary Rehabilitation. Pulmonary rehabilitation. Thorax. 2001;56(11):827-834.

29. Woodard CM, Berry MJ. Enhancing adherence to prescribed exercise: structured behavioral interventions in clinical exercise programs J Cardiopulm Rehabil. 2001;21(4):201-209.

30. Cote CG, Celli BR. Pulmonary rehabilitation and the BODE index in COPD. Eur Respir J. 2005;26(4):630-636.

31. Arnold E, Bruton A, Ellis-Hill C. Adherence to pulmonary rehabilitation: A qualitative study. Respir Med. 2006;100(10):1716-1723.

32. Foglio K, Bianchi L, Bruletti G, et al. Seven-year time course of lung function, symptoms, health-related quality of life, and exercise tolerance in COPD patients undergoing pulmonary rehabilitation programs. Respir Med. 2007;101(9):1961-1970.

33. Bourbeau J, Julien M, Maltais F, et al. Reduction of hospital utilization in patients with chronic obstructive pulmonary disease: a disease-specific self-management intervention. Arch Intern Med. 2003;163(5):585-591.

34. Langer D, Hendriks E, Burtin C, et al. A clinical practice guideline for physiotherapists treating patients with chronic obstructive pulmonary disease based on a systematic review of available evidence. Clin Rehabil. 2009;23(5):445-462.

35. Halding AG, Wahl A, Heggdal K. 'Belonging'. 'Patients' experiences of social relationships during pulmonary rehabilitation. Disabil Rehabil. 2010;32(15):1272-1280.
International Journal of COPD

\section{Publish your work in this journal}

The International Journal of COPD is an international, peer-reviewed journal of therapeutics and pharmacology focusing on concise rapid reporting of clinical studies and reviews in COPD. Special focus is given to the pathophysiological processes underlying the disease, intervention programs, patient focused education, and self management protocols.

\section{Dovepress}

This journal is indexed on PubMed Central, MedLine and CAS. The manuscript management system is completely online and includes a very quick and fair peer-review system, which is all easy to use. Visi http://www.dovepress.com/testimonials.php to read real quotes from published authors. 